JUURNAL

of Health Inequalities

\title{
History of alcohol consumption and cancer burden in Italy
}

\author{
Matteo Malvezzi ${ }^{1}$, Eva Negri ${ }^{1,2,3}$, Carlo La Vecchia' \\ 'Department of Clinical Sciences and Community Health, Università degli Studi di Milano, Italy \\ 2Department of Humanities, Pegaso Online University, Naples, Italy \\ ${ }^{3}$ Department of Medical and Surgical Sciences, University of Bologna, Italy
}

\begin{abstract}
Introduction: Alcohol consumption was traditionally high in Mediterranean countries, particularly in France and Italy, but substantial declines have been observed over the last four decades.

Material and methods: We obtained official resident population and death certification data from the World Health Organization (WHO) database for 5 major alcohol-related cancer sites in Italy for the 1970-2017 period. We computed age-standardised (world population) mortality rates and applied a joinpoint model to identify changes in trends. Yearly pure alcohol per capita consumption data (total, beer, spirits and wine) for Italy over the 1961-2018 period were obtained from the WHO European Health for All database.

Results: Since the late 1970's, alcohol consumption has been declining substantially in Italy, from about 20 to 7 litres of ethanol per adult per day. In men upper-respiratory tract cancer mortality fell consistently over the last decade, oral cavity and pharyngeal cancer by $14 \%$ to $3.1 / 100,000$ men and 2,103 deaths; oesophageal cancer by $13 \%$ to $2.0 / 100,000$ and 1,409 deaths, and laryngeal cancer by $27 \%$ to $1.8 / 100,000$ men and 1,428 deaths in 2017. Liver cancer had a rate of 4.9/100,000 men (3,667 deaths) in 2017.

Conclusions: This decline in alcohol consumption led to substantial declines in cirrhosis and other chronic liver diseases including liver cancer, and in all major alcohol related cancers (oral cavity and pharynx, oesophagus, larynx, liver, and also breast) in the last few decades in Italy. However, the favourable trends in alcohol-related mortality in Italy and other Mediterranean countries are not reflected in Central-Northern Europe and the USA. Thus, alcohol remains a major cause of cancer and other diseases in Europe.
\end{abstract}

KEY WORDS: alcohol, cancer, mortality, Italy, trend.

ADDRESS FOR CORRESPONDENCE: Carlo La Vecchia, Department of Clinical Sciences and Community Health, Università degli Studi di Milano, Italy, e-mail: carlo.lavecchia@unimi.it

Supplementary materials (slides from the conference) are available in Webbappendix at the Journal's website: https://www.termedia.pl/ Journal/Journal_of_Health_Inequalities-100

\section{INTRODUCTION}

Alcohol is a major cause of cancer worldwide, in particular it is strongly related to cancers of the upper digestive and respiratory tract and liver, and has a relevant role in breast cancer too [1-3].

Alcohol consumption was traditionally high in Mediterranean countries, particularly in France and Italy, but substantial declines have been observed over the last four decades [4]. The pattern and implications of alcohol drink- ing are also peculiar in these countries, with regular (rather than binge) drinking at meals, and with wine being the most common type of alcoholic beverage in most regions [5].

Here we report and discuss the historic patterns in mortality for the major alcohol-related cancers in Italy.

\section{MATERIAL AND METHODS}

We obtained official resident population and death certification data from the World Health Organization 
TABLE 1. Pure alcohol consumption in litres per adult age 15+, total and in strata (beer, wine and spirits) (with \% of total)

\begin{tabular}{|l|c|c|c|c|}
\hline Year & Total litres & Beer litres (\%) & Spirits litres (\%) & Wine litres (\%) \\
\hline 1965 & 18.42 & $0.57(3.1)$ & $1.85(10.0)$ & $16(86.9)$ \\
\hline 1970 & 19.72 & $0.75(3.8)$ & $2.39(12.1)$ & $16.58(84.1)$ \\
\hline 1975 & 18.32 & $0.84(4.6)$ & $2.38(13)$ & $15.1(82.4)$ \\
\hline 1980 & 16.73 & $1.07(6.4)$ & $2.44(14.6)$ & $13.15(78.6)$ \\
\hline 1985 & 13.22 & $1.37(10.4)$ & $1.62(12.3)$ & $10.29(77.8)$ \\
\hline 1990 & 10.99 & $1.5(13.6)$ & $1.19(10.8)$ & $8.22(74.8 \%)$ \\
\hline 1995 & 9.62 & $1.49(15.5)$ & $0.94(9.8)$ & $7.19(74.7)$ \\
\hline 2000 & 9.78 & $1.64(16.8)$ & $1.07(10.9)$ & $7.06(72.2)$ \\
\hline 2005 & 8.65 & $1.73(20.0)$ & $1.07(12.4)$ & $5.85(67.6)$ \\
\hline 2010 & 6.95 & $1.66(23.9)$ & $0.84(12.1)$ & $4.45(64.0)$ \\
\hline 2015 & 7.14 & $1.79(25.1)$ & $0.74(10.4)$ & $4.62(64.7)$ \\
\hline
\end{tabular}

(WHO) database for 5 major alcohol related cancer sites in Italy for the 1970-2017 period [6]. We recoded cancer deaths according to the $10^{\text {th }}$ International Classification of Disease (ICD) Revision: oral cavity and pharynx (ICD codes $\mathrm{C} 00-\mathrm{C} 14)$, oesophagus (C15), liver (C22), larynx (C32) and breast (C50) [7].

Yearly pure alcohol per capita consumption data (total, beer, spirits and wine) for Italy over the 1961-2018 period were obtained from the WHO European Health for All database (HFA-DB) [8].

We computed sex-specific death rates for each 5-year age group (from 0-4 up to 85+ years) and calendar year or quinquennium. Age standardised (Segi 1960 world standard population) mortality rates were calculated for all ages [9].

A joinpoint regression model was used to analyze the death rate trends over the studied period [10]. For a trend described by the relationship $y=a+b x$, where $y$ is $\ln$ (rate) and $x$ is the calendar year, the estimated annual percent change (EAPC) is calculated by $100 \times\left(\mathrm{e}^{\mathrm{b}}-1\right)$. The average annual percent change (AAPC), based on an underlying joinpoint model, was also calculated as the geometric weighted average of the EAPCs, with the weights equal to the lengths of each time interval segment [11]. Joinpoint regression can be used to identify those points, called the 'joinpoints', where the linear slope of the trend increases or decreases significantly. Models with a maximum of 4 joinpoints (corresponding to up to 5 different trends) were considered.

\section{RESULTS}

Table 1 displays yearly pure alcohol consumption per capita in the Italian population over 15 years of age in the years $1965,1970, \ldots, 2015$. Consumption is given for total, wine, beer and spirits in litres per capita and percentage of total.

Figure 1 illustrates the same yearly pure alcohol consumption data in litres per capita for total, wine, beer and spirits consumption in over 15 year old Italians from
1961 to 2018. Total consumption was stable throughout the 1960s with a peak at 19.7 litres of pure alcohol per capita in 1970, and a substantial fall to 6.95 in 2010 and a slight rise up to the most recent years 7.1 in 2015 . Wine made up for the greatest part of Italian alcoholic consumption, $87 \%$ in 1965 at 16 litres per capita, and falling both in absolute consumption to 4.6 litres and proportion $65 \%$ in 2015 . Beer consumption rose throughout the whole period in both quantity and relative share, rising from 0.6 litres per capita and 3\% in 1965 to 1.8 and 25\% in 2015 , overtaking spirits in the late ' 80 s. Spirits reached their peak in consumption in the early 1980s (2.4 litres per capita $15 \%$ of the total) to then fall to 0.7 litres and $10 \%$ of total litres of pure alcohol consumed in 2015.

Table 2 gives the all-ages standardised mortality rates and average yearly deaths for the 2005-2007 and 2010-2015 quinquenniums, and 2017 for major alcohol-related cancers in men and women in Italy, with the percentage difference between 2005-2009 and 2017. In men oral cavity and pharynx, oesophagus and larynx

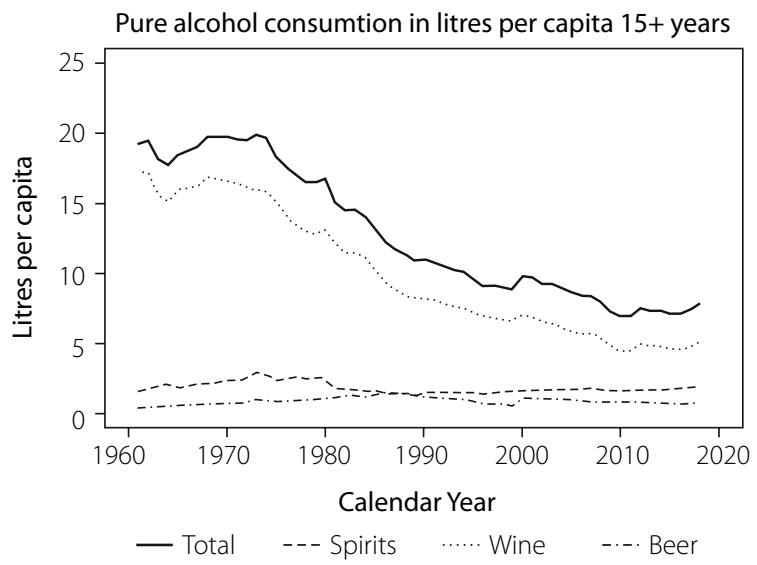

FIGURE 1. Trends in pure alcohol consumption in the Italian population aged $15+$ years in litres per capita, total (full line) and in strata of beer (dotted-dashed line) spirits (dashed line) and wine (dotted line) 
TABLE 2. Quinquennial age-standardised mortality rates, average annual deaths for select alcohol-related cancers, and percent difference between 2005-2009 and 2017

\begin{tabular}{|c|c|c|c|c|c|c|c|c|}
\hline \multirow{2}{*}{ Sex } & \multirow[b]{2}{*}{ Cancer } & \multicolumn{2}{|c|}{ 2005-2009 } & \multicolumn{2}{|c|}{ 2010-2015 } & \multicolumn{2}{|c|}{2017} & \multirow{2}{*}{$\begin{array}{c}2017 \\
\text { vs 2005-2009 } \\
\% \text { Difference }\end{array}$} \\
\hline & & ASR & $\begin{array}{c}\text { Average } \\
\text { deaths }\end{array}$ & ASR & $\begin{array}{c}\text { Average } \\
\text { deaths }\end{array}$ & ASR & $\begin{array}{l}\text { Average } \\
\text { deaths }\end{array}$ & \\
\hline \multirow[t]{4}{*}{ Men } & Oral cavity pharynx & 3.59 & 1,958 & 3.25 & 1,971 & 3.10 & 2,103 & -13.6 \\
\hline & Oesophagus & 2.26 & 1,340 & 2.08 & 1,376 & 1.96 & 1,409 & -13.3 \\
\hline & $\begin{array}{l}\text { Liver specified } \\
\text { as primary }\end{array}$ & 4.89 & 3,073 & 6.08 & 4,153 & 4.91 & 3,667 & 0.4 \\
\hline & Larynx & 2.50 & 1,568 & 2.05 & 1,421 & 1.83 & 1,428 & -26.8 \\
\hline \multirow[t]{5}{*}{ Women } & Oral cavity pharynx & 0.97 & 780 & 0.98 & 866 & 1.13 & 1,103 & 16.5 \\
\hline & Oesophagus & 0.48 & 434 & 0.44 & 449 & 0.50 & 512 & 4.2 \\
\hline & $\begin{array}{l}\text { Liver specified } \\
\text { as primary }\end{array}$ & 1.55 & 1,495 & 1.88 & 2,009 & 1.56 & 1,780 & 0.6 \\
\hline & Larynx & 0.18 & 154 & 0.20 & 171 & 0.19 & 186 & 5.6 \\
\hline & Breast & 16.06 & 11,826 & 14.82 & 12,052 & 14.39 & 12,841 & -10.4 \\
\hline
\end{tabular}

ASR - age-standardised rate

cancer mortality fell consistently over the last decade of available data, by $14 \%, 13 \%$ and $27 \%$ respectively. In 2017 mortality rates and corresponding numbers of deaths were 3.1/100,000 men (2,103 deaths) for oral cavity and pharynx, 2.0 (1,409 deaths) for oesophagus, and $1.8 / 100,000$ men (1,428 deaths) for laryngeal cancer. The liver cancer mortality rate was 4.9 in $2005-2009$, it rose to 6.1 in 2010-2014 and fell back to 4.9/100,000 men corresponding to 3,667 deaths in 2017. In women liver cancer age-standardised mortality rates were $1.6 / 100,000$ women in 2005-2009 rising about $20 \%$ and falling back down to the same level in 2017 corresponding to 1,780 deaths. In women, oral cavity and pharynx, oesophagus and larynx cancers all showed rising mortality rates over the last decade. Oral cavity and pharynx rose $17 \%$ to $1.1 / 100,000$ women and 1,103 deaths in 2017, while oesophagus and larynx rose about $5 \%$ to $0.5 / 100,000$ and 512 deaths, and 0.2 and 186 deaths respectively. Breast cancer fell $10 \%$ over the last ten years to 14.4 deaths/100,000 women corresponding to 12,841 deaths in 2017 .

Table 3 and Figure 2 illustrate the joinpoint analyses for the age standardised mortality rate trends of the 5 examined alcohol related cancers in men and women over the 1970-2017 period in Italy. In men oral cavity and pharynx, oesophagus and larynx cancers had a similar trend pattern. They were either flat or slightly rising up to the mid 1980s and then had descending favourable trends with the most recent trend either being less steep or levelling off after the late 2000s. However, all three cancers had favourable overall AAPCs for the whole period: oral cavity and pharynx had an AAPC of $-1.4 \%$, oesophagus $-1.9 \%$ and larynx $-2.7 \%$. In men liver cancer rose sharply (EAPC - 4.5\%) to a first highest peak in mortality in 1994 and descended just as fast (EAPC
- 4.7) to 2008, to then draw a similar but lower peak in 2012 finishing with a descending trend (EAPC -8.3\%). The overall trend for liver cancer was a flat non-significant AAPC of $0.7 \%$. The pattern for liver cancer was similar in women with a slight rise (EAPC - 1.1\%) up to 1994 a consistent descent (EAPC - 3.9\%) to 2008, followed by steep rise to 2012 with a fall of about the same magnitude, and both not significant, like the overall AAPC of $-0.7 \%$. In women, oral cavity and pharynx cancer mortality showed a stable oscillatory pattern reflected by the non-significant 0.4 AAPC. Female oesophageal cancer showed a significant favourable trend (EAPC 1.9\%) between 1978 and 2014 followed by a brief sharp non-significant rise to 2017 corresponding to a favourable overall AAPC (-1\%). Laryngeal cancer mortality in women also showed a consistent descending (EAPC $-2.2 \%$ ) trend from 1974 to 1999 to then flatten out till 2017, with an overall favourable (AAPC - 0.8\%) trend for the whole period. Breast cancer mortality rose significantly up to 1989 plateaued up to 1995 and then showed consistent significant descents until 2017, leading to a modest, but significant overall AAPC of $-0.5 \%$.

\section{DISCUSSION}

In 2016 an estimated 291,000 people died of alcohol attributable causes in the EU plus Switzerland and Norway, of these nearly $30 \%$ were due to cancer, followed by cirrhosis and liver failure at about $20 \%$ [12]. About $6 \%$ of all cancer deaths are attributable to alcohol in the EU ( $8 \%$ for men and 3.6\% for women) [2, 3]. However alcohol consumption is heterogeneous in Europe with southern countries having lower consumptions while the central and eastern countries show high alcohol consumption levels $[4,12]$. In particular Italy and France showed 


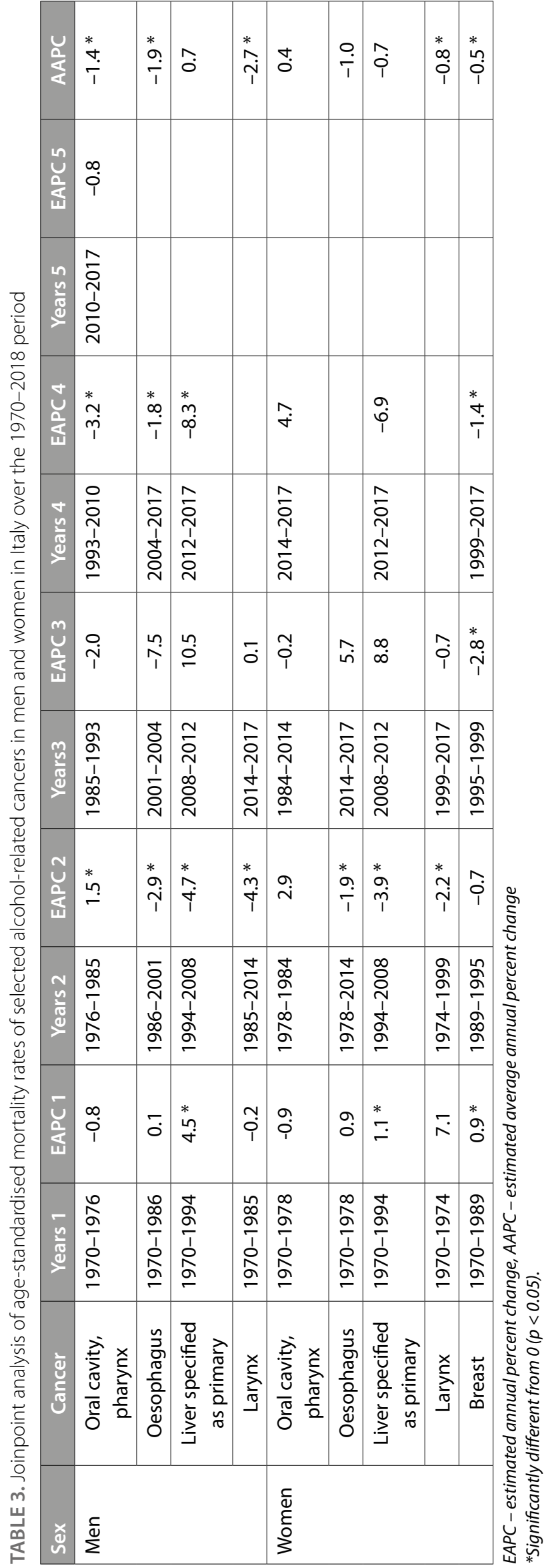

strong declines in alcohol consumption over the last 3 decades. Since the late 1970's, alcohol consumption has been declining substantially by about two thirds in Italy, from over 20 liters of ethanol per adult per day down to 7. The real fall in alcohol consumption may indeed have been greater, due to the substantial decrease in auto production and consumption over the last four decades. A major reason for the decline in alcohol consumption in Italy has been the avoidance of drinking at lunch, due to social and labour changes, despite an absence of systematic new regulations. In addition, the new generations start drinking later and do not tend to drink regularly. Similarly to the rest of Europe Italian males are more frequently consumers than females ( $79 \%$ of males over 11 years old are consumers vs $55 \%$ of women), and about $15 \%$ males are regular heavy drinkers vs $6 \%$ of females [13]. However, women appear to be less aware of the link between alcohol and cancer than men $[14,15]$.

This decline in alcohol consumption led to substantial falls in mortality from cirrhosis and other chronic liver diseases including liver cancer [16, 17], and in all major alcohol related cancers (oral cavity and pharynx, oesophagus, larynx, liver, and also breast) in the last few decades in Italy. The effect of the reduction in alcohol is most felt in head and neck cancers where it has a multiplicative effect with tobacco smoking and reductions in one risk factor can bring about very strong changes in risk. This is evident in men where these cancers (oral cavity and pharynx, oesophagus and larynx) all showed favourable trends, both recently and over the whole period, also due to the favourable changes in tobacco consumption $[18,19]$. In women the trends are not so favourable over the whole period, and in the last decade where rises for these cancers were recorded, these were probably due to the changed prevalence of tobacco. Consequently the male to female sex ratios tended to fall over the considered period [20]. The fall in alcohol drinking is therefore also a minor contributing factor to the fall in breast cancer mortality in southern Europe [21]. However, the favourable trends in alcohol-related mortality in Italy and other Mediterranean countries are not reflected in Central-Northern Europe and the USA [13, 22, 23]. Thus, alcohol remains a major cause of cancer and other diseases in Europe [2, 3].

\section{ACKNOWLEDGEMENTS}

This work was conducted with the contribution of the Italian Association for Cancer Research (AIRC, project N. 22987), MIUR (Ministero dell'Istruzione, dell'Università e della Ricerca), with a SIR (Scientific Independence of Young Researchers) 2014 grant (project RBSI1465UH).

\section{DISCLOSURE}

The authors report no conflict of interest. 
A

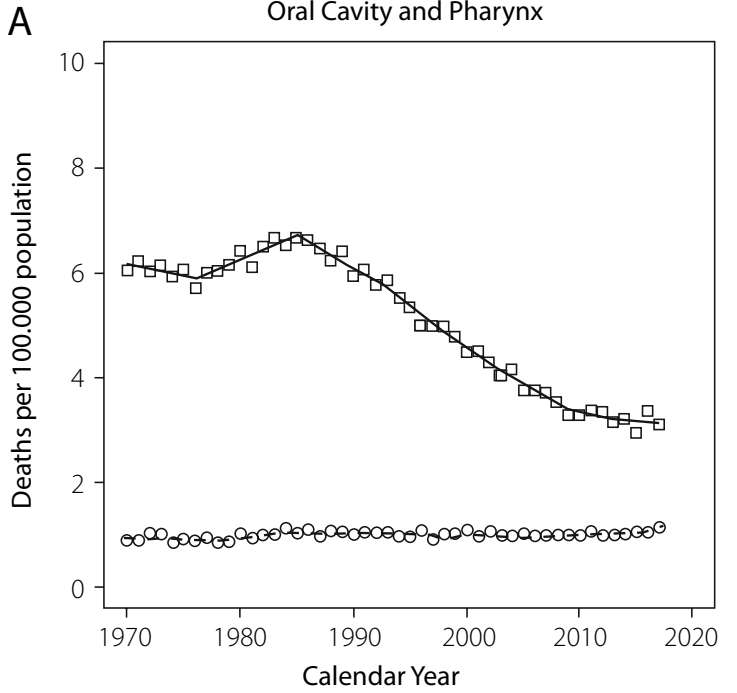

口 Male rate o Female rate

— Male joinpoint model _ - Female joinpoint model

C

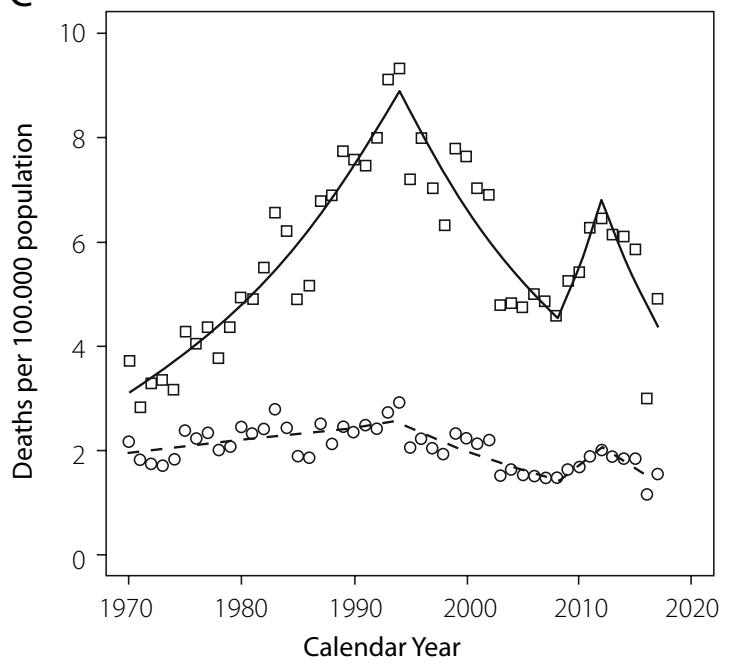

$\square$ Male rate o Female rate

— Male joinpoint model _ - Female joinpoint model

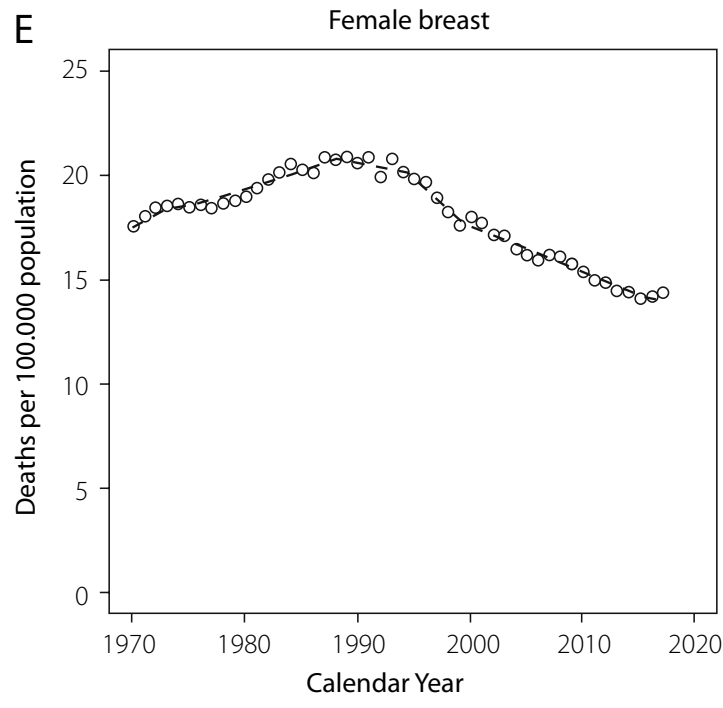

$\square$ Male rate o Female rate

— Male joinpoint model _ - Female joinpoint model

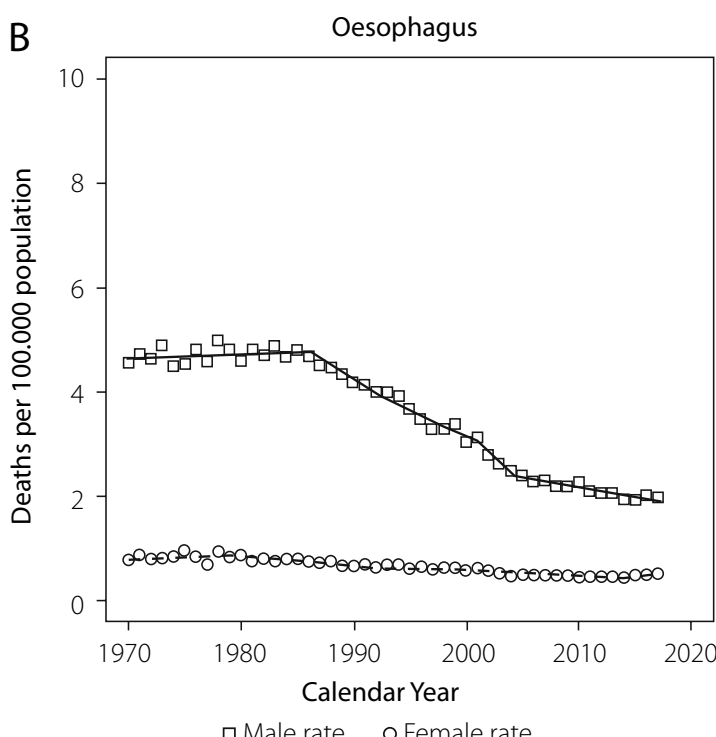

a Male rate o Female rate

— Male joinpoint model - - Female joinpoint model

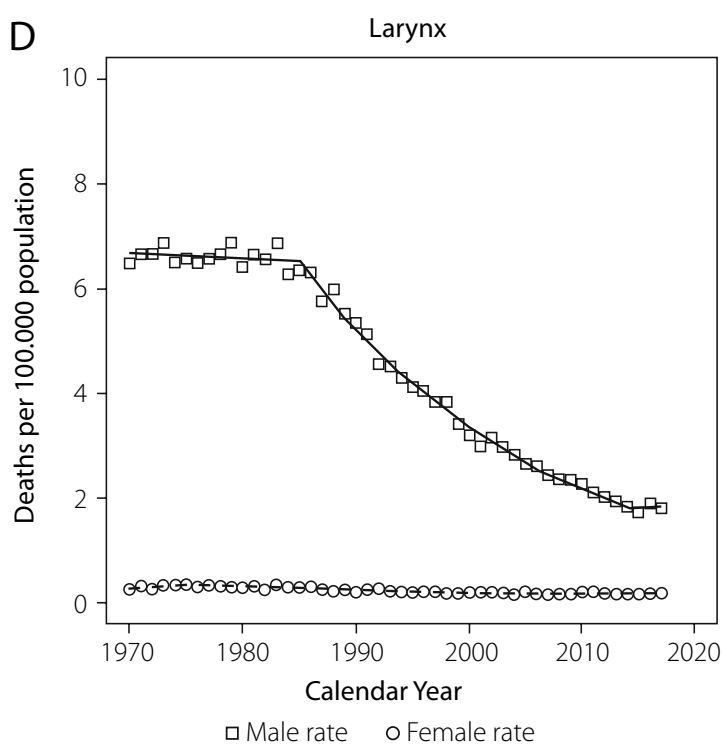

— Male joinpoint model _ - Female joinpoint model

FIGURE 2. Age standardised rates for selected alcohol related cancers in Italy, over the 1970-2018 period for men (squares) and women (circles) and the estimated joinpoint models (men full line, women dotted line) 


\section{References}

1. Bagnardi V, Rota M, Botteri E, et al. Alcohol consumption and site -specific cancer risk: a comprehensive dose-response meta-analysis. Br J Cancer 2015; 112(3): 580-593.

2. Praud D, Rota M, Rehm J, et al. Cancer incidence and mortality attributable to alcohol consumption. Int J Cancer 2016; 138(6): 1380-1387.

3. Rumgay H, Shield K, Charvat H, et al. Global burden of cancer in 2020 attributable to alcohol consumption: a population based study. Lancet Oncol 2021; 22(8): 1071-1080.

4. La Vecchia C, Bosetti C, Bertuccio P, et al. Trends in alcohol consumption in Europe and their impact on major alcohol-related cancers. Eur J Cancer Prev 2014; 23(4): 319-322.

5. Giacosa A, Barale R, Bavaresco L, et al. Cancer prevention in Europe: the Mediterranean diet as a protective choice. Eur J Cancer Prev 2013; 22(1): 90-95.

6. World Health Organization Statistical Information System. WHO mortality database. Geneva: World Health Organization Available from: http:/wwwwhoint/healthinfo/statistics/mortality_rawdata/en/indexhtml (accessed: 25 June 2021).

7. World Health Organization. International Classification of Disease and related Health Problems: $10^{\text {th }}$ revision. World Health Organization, Geneva 1992.

8. World Health Organization. European health for all database (HFA-DB). Available from: https://wwweurowhoint/en/ data-and-evidence/databases/european-health-for-all-familyof-databases-hfa-db (accessed: 20 September 2021).

9. Esteve J, Benhamou E, Raymond L. Statistical methods in cancer research. Volume IV. Descriptive epidemiology. IARC Sci Publ 1994; 128: 1-302.

10. Kim HJ, Fay MP, Feuer EJ, Midthune DN. Permutation tests for joinpoint regression with applications to cancer rates. Stat Med 2000; 19(3): 335-351.

11. Clegg LX, Hankey BF, Tiwari R, et al. Estimating average annual per cent change in trend analysis. Stat Med 2009; 28(29): 3670-3682

12. World Health Organization. Status report on alcohol consumption, harm and policy responses in 30 European countries 2019. World Health Organization, Copenhagen 2019.

13. Santucci C, Malvezzi M, Wojtyla C, et al. Persisting cancer mortality gap between western and eastern Europe. Eur J Cancer 2021; In Press 2022.

14. La Vecchia C, Anelli M, Zuccato E, et al. Perceived risk of cancer in population samples from 5 European countries. Int J Cancer 2000; 86(5): 747-748.

15. Scheideler JK, Klein WMP. Awareness of the link between alcohol consumption and cancer across the world: a review. Cancer Epidemiol Biomarkers Prev 2018; 27(4): 429-437.

16. Turati F, Galeone C, Rota M, et al. Alcohol and liver cancer: a systematic review and meta-analysis of prospective studies. Ann Oncol 2014; 25(8): 1526-1535.

17. Baecker A, Liu X, La Vecchia C, Zhang ZF. Worldwide incidence of hepatocellular carcinoma cases attributable to major risk factors. Eur J Cancer Prev 2018; 27(3): 205-212.

18. Lugo A, Zuccaro P, Pacifici R, et al. Smoking in Italy in 20152016: prevalence, trends, roll-your-own cigarettes, and atti- tudes towards incoming regulations. Tumori 2017; 103(4): 353359.

19. Marcon A, Pesce G, Calciano L, et al. Trends in smoking initiation in Europe over 40 years: A retrospective cohort study. PLoS One 2018; 13(8): e0201881.

20. Carioli G, Bertuccio P, Levi F, et al. Cohort analysis of epithelial cancer mortality male-to-female sex ratios in the European Union, USA, and Japan. Int J Environ Res Public Health 2020; 17(15): 5311.

21. Freudenheim JL. Alcohol's effects on breast cancer in women. Alcohol Res 2020; 40(2): 11

22. Bertuccio P, Alicandro G, Malvezzi M, et al. Cancer mortality in Europe in 2015 and an overview of trends since 1990. Ann Oncol 2019; 30(8): 1356-1369.

23. Islami F, Ward EM, Sung $\mathrm{H}$, et al. Annual report to the nation on the status of cancer, part 1: National Cancer Statistics. J Natl Cancer Inst 2021; 113(12): 1648-1669.

\section{AUTHORS' CONTRIBUTIONS}

CLV, EN and MM prepared the concept of the paper. MM collected, analysed the data and wrote the original draft. CLV and EN critically revised the text and approved the final manuscript. 